\title{
Separation of active constituents in some medicinal plants by thin layer chromatography
}

\author{
Tien T. Tran, Nhan T. T. Nguyen, Tien T. Ha, \& Lan T. Q. Tran*
}

Department of Veterinary Biosciences, Nong Lam University, Ho Chi Minh City, Vietnam

ARTICLE INFO
Research Paper
Received: April 02, 2018
Revised: April 20, 2018
Accepted: April 23, 2018
Keywords
Camellia sinensis
Citrus aurantifolia
Constituent
Rhodomyrtus tomentosa
Thin Layer Chromatography (TLC)

\section{${ }^{*}$ Corresponding author}

Tran Thi Quynh Lan Email: lan.tranthiquynh@hcmuaf.edu.vn

\begin{abstract}
Separation and identification of the active pharmacological compounds from some medicinal plants (Citrus aurantifolia, Rhodomyrtus tomentosa, Camellia sinensis) by Thin Layer Chromatography (TLC) showed the yields of crude extracts obtained from Citrus aurantifolia, Rhodomyrtus tomentosa and Camellia sinensis leaves at 1.5\%, 5.62\% and $10.4 \%$ respectively. Toluene: ethyl acetate (93:7) (v:v) solvent was suitable for the separation of active compounds in crude extract of Citrus aurantifolia, Rhodomyrtus tomentosa leaves while chloroform: ethylacetate: formic acid (5:4:1) (v:v:v) solvent was suitable for the extraction of active compounds in crude extract from Camellia sinensis leaves. Furthermore, the results showed that the number of compounds in extract from Citrus aurantifolia were likely affected by the vacuum evaporator effects. The TLC fingerprints of all three medicinal plants had the same visual ability when the fingerprint detected by UV $(\lambda=254 \mathrm{~nm})$ and the reagent containing $0.1 \mathrm{~g}$ vanillin in $28 \mathrm{~mL}$ of methanol: $1 \mathrm{~mL}$ of sulfuric acid. In brief, the three active compounds including citral (Citrus aurantifolia), rhdomyrtone (Rhodomyrtus tomentosa) and catechin hydrate (Camellia sinensis) contained in the extract of 3 medicinal herbs had the limited detection (LOD) at 195 $\mathrm{ng} / \mathrm{spot}, 321.5 \mathrm{ng} / \mathrm{spot}$ and $625 \mathrm{ng} / \mathrm{spot}$, respectively.
\end{abstract}

Cited as: Tran, T. T., Nguyen, N. T. T., Ha, T. T., \& Tran, L. T. Q. (2018). Separation of active constituents in some medicinal plants by thin layer chromatography. The Journal of Agriculture and Development 17(5), 60-67. 


\title{
Phân tách thành phần hoạt chất một số cây dược liệu bằng phương pháp sắc ký bản mỏng
}

\author{
Trần Thanh Tiến, Nguyễn Trần Thảo Nhân, Hà Thị Tiền \& Trần Thị Quỳnh Lan ${ }^{1 *}$ \\ Bộ Môn Khoa Học Sinh Học Thú Y, Trường Đại Học Nông Lâm TP. Hồ Chí Minh, TP. Hồ Chí Minh
}

\section{THÔNG TIN BÀI BÁO}

Bài báo tổng quan

Ngày nhận: 02/04/2018

Ngày chỉnh sửa: 20/04/2018

Ngày chấp nhận: 23/04/2018

\section{Từ khóa}

Chanh

Hoạt chất

Sim

Thin Layer Chromatography (TLC)

Trà xanh

*Tác giả liên hệ

Trần Thị Quỳnh Lan

\section{TÓM TẮT}

Phân tách và xác định một số hoạt chất có tác động dược học từ chiết xuất của một số cây dược liệu (chanh, sim và trà xanh) bằng kỹ thuật sắc ký bản mỏng (Thin Layer Chromatography, TLC) cho thấy hiệu suất khi thu hồi cao từ lá chanh, lá sim và lá trà xanh ở mức $1,5 \%, 5,62 \%$ và $10,4 \%$. Hệ dung môi toluen: ethyl acetate (93:7) (v:v), phù hợp để phân tách các hoạt chất trong cao thô chiết xuất từ lá chanh và lá sim; hệ dung môi chloroform: ethyl acetate: acid formic (5:4:1) (v:v:v) phù hợp trong phân tách hoạt chất trong cao thô chiết xuất từ lá trà xanh. Ngoài ra, cô quay chân không có thể làm thay đổi số lượng các hoạt chất trong thành phần dịch chiết lá chanh. Sắc ký đồ của dịch chiết lá chanh, sim và trà xanh cho kết quả tương đương khi phát hiện trên bản mỏng sắc ký bằng buồng soi UV $(\lambda=254 \mathrm{~nm})$ và thuốc thử $0,1 \mathrm{~g}$ vanillin trong $28 \mathrm{~mL}$ methanol: $1 \mathrm{~mL}$ sulfuric acid. Ba hoạt chất có đặc tính dược học bao gồm citral (chanh), rhdomyrtone ( $\operatorname{sim}$ ) và catechin hydrate (trà xanh) có trong thành phần tách chiết của 3 dược liệu có giới hạn phát hiện (LOD) ở mức $195 \mathrm{ng} /$ vệt, 321,5 ng/vệt và n625 ng/vệt sắc ký đồ.

\section{1. Đặt Vấn Đề}

Sử dụng cây dược liệu trong phòng và trị bệnh trên vật nuôi đang là một trong những giải pháp được quan tâm nhằm thay thế cho nhiều dược phẩm và kháng sinh đã bị đề kháng (Sibanda \& ctv., 2007; Matthew \& ctv., 2017).

Nguồn cây dược liệu ở các quốc gia nhiệt đới như Việt Nam rất phong phú và đa dạng (Do, 2004). Tuy nhiên, việc tận dụng các nguồn dược liệu sã̃n có này trong lĩnh vực chăn nuôi thú y hiện nay vẫn còn giới hạn về chủng loại cây dược liệu. Nguyên nhân chính làm giới hạn khả năng sử dụng cây dược liệu là do thành phần và hàm lượng các hoạt chất có khả năng kháng khuẩn, kháng viêm và các tác dụng dược lực khác (kể cả độc tính) của các dược liệu này vẫn chưa được hiểu rõ do hạn chế về phương pháp phân tích. Một số phương pháp truyền thống (soi vi phẫu, hóa học,...) cho kết quả có độ chính xác chưa cao trong khi các phương pháp hiện đại khác như sắc ký lỏng hiệu năng cao (HPLC) lại cần nhiều trang thiết bị, chất chuẩn đối chiếu, thao tác khá phức tạp và đắt tiền. Nhu cầu đặt ra là cần phải có một phương pháp thực hiện đơn giản hơn, chí phí thấp nhưng cho kết quả chính xác và có độ tin cậy cao.

Sắc ký lớp mỏng (thin layer chromatography) là một trong những phương pháp ứng dụng thường xuyên trong phân tích và kiểm nghiệm dược liệu vì có những ưu điểm như dễ thực hiện, độ nhạy và đặc hiệu cao, thời gian phân tích nhanh và chi phí phân tích thấp so với các phương pháp khác (Wagner \& Bladt, 1996; Ashray, 2012). Sử dụng phương pháp TLC để phân tách thành phần hoạt chất của 3 loại cây (trà xanh, chanh và sim) và xác định một loại hoạt chất chính có hoạt tính dược lực (citral, catechin, rhodomyrtone) trong từng loại cây này sẽ đem đến khả năng ứng dụng trong thú y dể thay thế các dược phẩm và tăng giá trị kinh tế của các cây dược liệu sã̃n có. 


\section{Vật Liệu và Phương Pháp Nghiên Cứu}

\subsection{Chuẩn bị mẫu}

Nguyên liệu: lá chanh ta (Citrus aurantifolia), lá sim (Rhodomyrtus tomentosa), lá trà xanh (Camellia sinensis) có nguồn gốc từ tỉnh Lâm Đồng. Nguyên liệu sau đó được rửa sạch dưới vòi nước, để ráo nước ở nhiệt độ phòng, sau đó xay nhỏ.

\subsection{Chiết xuất hoạt chất từ cây dược liệu}

Chiết xuất hoạt chất từ cây dược liệu được thực hiện theo phương pháp ngâm với dung môi chiết xuất acetone. Đầu tiên, cân chính xác $50 \mathrm{~g}$ mẫu đã chuẩn bị cho vào bình tam giác (1.000 mL), tiếp tục cho thêm $500 \mathrm{~mL}$ acetone (Xilonh, Trung Quốc) (Eloff, 1988). Bình chứa hỗn hợp dung dịch sau đó được lắc đều, lọc bằng giấy lọc (Hangzhou Special Paper Industry, Trung Quốc); dịch qua lọc (dịch chiết) được thu nhận và bảo quản trong bình thuỷ tinh $(1.000 \mathrm{~mL})$ ở $4^{0} \mathrm{C}$.

Dịch chiết dược liệu của mỗi loại nguyên liệu được chia thành hai phần thể tích bằng nhau. Một phần được loại bỏ dung môi bằng hệ thống cô quay chân không (Stuart, Anh) (Auemphon \& ctv., 2015) ở điều kiện nhiệt độ phòng để thu nhận cao thô nhằm đánh giá sự biến đổi thành phần hoạt chất của dịch chiết dược liệu dưới tác động của cô quay chân không; phần dịch chiết còn lại sẽ sử dụng trực tiếp để phân tích bằng phương pháp TLC.

Hiệu suất cao thô $(\%)=\frac{\mathrm{m} \times 100}{0,5 \times \mathrm{M}}$ (Charles, 2012)

Trong đó:

m: trọng lượng cao thô thu được sau khi cô quay chân không.

M: trọng lượng mẫu dược liệu ban đầu.

\subsection{Phân tách thành phần hoạt chất từ chiết xuất cao thô bằng phương pháp TLC}

\subsubsection{Pha loãng cao thô}

Cao thô thu nhận sau cô quay được pha loãng thành nồng độ $20 \mathrm{mg} / \mathrm{mL}$ bằng acetone (Eloff \& ctv., 2011) sau đó được lọc qua đầu lọc có đường kính $0,22 \mu \mathrm{m}$ để chuẩn bị thực hiện sắc ký.

\subsubsection{Phương pháp thực hiện}

Cao thô (nồng độ $20 \mathrm{mg} / \mathrm{mL}$ ) hoặc dịch chiết tươi của các loại dược liệu được phun lên bề mặt bản mỏng aluminium backed silica gel 60 F254 (Merck, Đức) (Eloff \& ctv., 2011) trên hệ thống máy sắc ký bản mỏng bán tự động (Camag, Thụy Sĩ), thể tích phun $5 \mu \mathrm{L} /$ vệt, tốc độ phun 250 nL/giây, dộ rộng vệt phun 8 mm (Hướng dẫn sử dụng Camag, Thụy Sĩ). Bản mỏng sau khi được phun mẫu được để khô tự nhiên ở nhiệt độ phòng, sau đó được đặt trong bình hai đáy kích thước 20 $\times 10 \mathrm{~cm}$ chứa dung môi khai triển cho phép các hoạt chất trong mẫu di chuyển và phân tách trên bản mỏng tuỳ theo độ phân cực. Khả năng phân tách hoạt chất được đánh giá trên hai hệ dung môi khai triển dùng ngâm bản mỏng: (1) chloroform: ethylacetate: acid formic (5:4:1) (v:v:v) (CEF) (Eloff \& ctv., 2011) và (2) toluen: ethylacetate (93:7) (v:v) (TE) (Wagner \& Bladt, 1996).

\subsection{3. Đọc kết quả TLC}

Kết quả phân tách hoạt chất trên sắc ký đồ được quan sát bằng buồng soi UV (Camag, Thụy Sĩ) với bước sóng $254 \mathrm{~nm}$ (VPC, 2009) hoặc quan sát bằng mắt thường sau khi phun thuốc thử vanillin $0,1 \mathrm{~g}$ trong $28 \mathrm{~mL}$ methanol: $1 \mathrm{~mL}$ sulfuric acid (Eloff \& ctv., 2011).

2.4. Xác định sự hiện diện hoạt chất chính có tác dụng dược lý từ thành phần chiết xuất của mỗi loại cây dược liệu

\subsubsection{Chọn hoạt chất chính có hoạt lực dược lý} cho mỗi loại chiết xuất dược liệu

Hoạt chất chính có tác động dược lý có trong dịch chiết từ mỗi loại cây dược liệu được lựa dựa trên hoạt tính kháng khuẩn. Một số nghiên cứu gần đây cho thấy rhodomyrtone có trong cao chiết từ lá sim có hiệu quả kháng khuẩn tốt đối với một số vi khuẩn gram dương (Surasak \& ctv., 2009; Hiranrat, 2010; Surasak \& ctv., 2012) dặc biệt là $S$. aureus kháng methicillin (methicillinresistant Staphylococcus aureus - EMRSA), S. aureus kháng vancomycin (vancomycinintermediate Staphylococcus aureus - VSA) và enterococcus kháng vancomycin (vancomycinresistant enterococcus - VRE) (Sukanlaya \& ctv., 2013). Ngoài ra, các loại catechin trong trà xanh đã được chứng minh là có tác dụng gây tổn hại màng tế bào, ức chế quá trình tổng hợp acid béo và ức chế hoạt động một số loại emzyme của vi khuẩn (Wanda, 
2014). Bên cạnh đó, tác dụng kháng khuẩn và kháng nấm của citral trong lá chanh cũng được chứng minh trong nhiều nghiên cứu khác nhau (Grace, 1989; Maria \& ctv., 2014; Chao \& ctv., 2016).

\subsubsection{Chất chuẩn đối chiếu}

Các chất chuẩn bao gồm: citral (ci) (tinh khiết 95\%) (C83007, Sigma, Mỹ), rhodomyrtone (rh) (tinh khiết $\geq 95 \%$ ) (SMB00114, Sigma, Mỹ) và catechin hydrate (ca) (tinh khiết $\geq 98 \%$ ) (C1252, Sigma, Mỹ) lần lượt được chọn làm chất chuẩn đối chiếu khi xác định sự hiện diện của các hoạt chất này trong dịch chiết thô của lá chanh, lá sim và lá trà xanh.

Các chất chuẩn được pha loãng trong acetone theo 12 mức nồng độ chuẩn từ cao đến thấp (catechin hydrate: $2 \mu \mathrm{g} / \mu \mathrm{l}, 1 \mu \mathrm{g} / \mu \mathrm{l} \ldots 0,001 \mu \mathrm{g} / \mu \mathrm{l}$; citral: $20 \mu \mathrm{g} / \mu \mathrm{l}, 10 \mu \mathrm{g} / \mu \mathrm{l} \ldots 0,01 \mu \mathrm{g} / \mu \mathrm{l}$ và rhodomyrtone: $1 \mu \mathrm{g} / \mu \mathrm{l}, 0,5 \mu \mathrm{g} / \mu \mathrm{l} \ldots 0,0004 \mu \mathrm{g} / \mu \mathrm{l})$.

Các dãy chất chuẩn có nồng độ giảm dần này được dùng trong xác định giới hạn phát hiện (Limit Of Detection, LOD) của các chất này theo phương pháp TLC. Giới hạn phát hiện của một chất (LOD) được xác định là nồng độ pha loãng cuối cùng tính trên 1 vệt sắc ký mà vẫn có thể phát hiện được trong một điều kiện thực hiện sắc ký nhất định. Giới hạn phát hiện được khẳng định bằng cách thực hiện TLC lập lại 10 lần đối với mức nồng độ được xác định là LOD.

\subsubsection{Phương pháp xác định sự hiện diện hoạt chất chính có tác dụng dược lý trong dịch chiết}

Sự hiện diện của hoạt chất có tác dụng dược lý (citral, rhodomyrtone, catechin) trong mẫu cao chiết được xác định dựa vào việc so sánh hệ số di chuyển Rf của vệt sắc ký với hệ số Rf của chất chuẩn đối chiếu.

Giới hạn phát hiện của citral, rhodomyrtone, catechin, cũng được xác định trong điều kiện sắc ký tối ưu đối với từng loại dược liệu.

\section{Kết Quả và Thảo Luận}

\subsection{Hiệu suất cao thô}

Hiệu suất cao thô của các dược liệu khảo sát được trình bày trong Bảng 1 . Kết quả cho thấy hiệu suất cao thô của lá trà xanh ở mức $10,4 \%$ cao hơn gấp 1,85 lần hiệu suất cao thô thu nhận từ lá sim và gấp 6,9 lần hiệu suất cao thô thu nhận từ lá chanh. Theo Eloff \& ctv. (2011), dược liệu khi chiết bằng acetone có số lượng hợp chất chiết được cao hơn khi chiết bằng các phương pháp và dung môi khác được đề nghị trong dược điển về thảo dược của Anh. Tuy nhiên, nghiên cứu của Asadhawut (2010) ghi nhận hiệu suất chiết cao thô từ lá sim trong dung môi acetone $(2,22 \%)$ thấp hơn so với khi chiết trong cồn (methanol) $(5,31 \%)$. Ngoài ra, hiệu suất cao thô còn phụ thuộc vào rất nhiều yếu khác nhau như thời điểm thu hái, trạng thái nguyên liệu (tươi/khô), phương pháp chiết...

Bảng 1. Hiệu suất của các loại cao thô

\begin{tabular}{lc}
\hline Dược liệu & Hiệu suất cao thô $(\%)$ \\
\hline Chanh & 1,50 \\
Sim & 5,62 \\
Trà xanh & 10,40 \\
\hline
\end{tabular}

\subsection{Phân tách thành phần hoạt chất từ chiết xuất cao thô bằng phương pháp TLC}

\subsection{1. Ảnh hưởng của cô quay chân không đến số lượng hoạt chất có trong thành phần dịch chiết}

Kết quả phân tách trên bản mỏng cho thấy không có sự khác biệt số lượng các hoạt chất trong dịch chiết lá sim và lá trà xanh khi sử dụng cô quay chân không để loại bỏ dung môi chiết xuất ở điều kiện nhiệt độ phòng (Bảng 2). Trong khi đó, nếu sử dụng bước loại bỏ dịch chiết bằng cô quay chân không cho kết quả phân tách các hoạt chất từ chiết xuất sim và trà xanh rõ nét và đậm màu hơn (Hình 1).

Bảng 2. Số lượng hoạt chất (số vệt) trong dịch chiết dược liệu khi phân tách bằng TLC

\begin{tabular}{lccc}
\hline \multirow{2}{*}{ Dược liệu } & \multirow{2}{*}{$\begin{array}{c}\text { Dung môi } \\
\text { khai triển }\end{array}$} & \multicolumn{2}{c}{$\begin{array}{c}\text { Sột sắc kýt hiện } \\
\text { phán }\end{array}$} \\
\cline { 3 - 4 } & & $\begin{array}{c}\text { Cồ } \\
\text { quay }\end{array}$ & $\begin{array}{c}\text { Không } \\
\text { cô quay }\end{array}$ \\
\hline Chanh & TE & 4 & 9 \\
Sim & TE & 10 & 10 \\
Trà xanh & CEF & 11 & 11 \\
\hline
\end{tabular}

Trái lại, khi phân tách thành phần hoạt chất từ chiết xuất lá chanh cho thấy có sự khác biệt rõ rệt trên sắc ký đồ giữa mẫu dịch chiết lá chanh thu nhận sau cô quay chân không và dịch chiết 


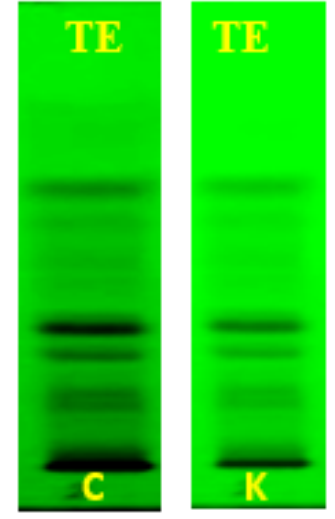

(I)

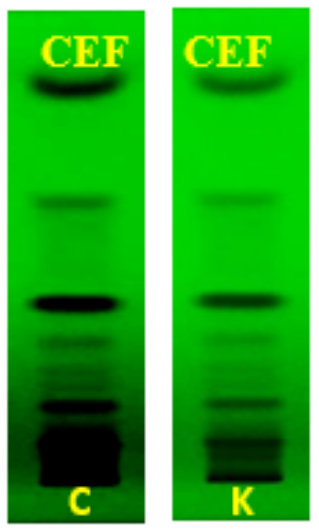

(II)
Hình 1. Kết quả phân tách hoạt chất trên sắc ký đồ của dịch chiết từ lá sim (I) và trà xanh (II) trải qua cô quay chân không $(\mathrm{C})$ và không cô quay chân không $(\mathrm{K})$ quan sát bằng UV $(\lambda=254 \mathrm{~nm})$.

tươi không qua cô quay chân không (Hình 2). Mẫu dịch chiết lá chanh qua cô quay chân không (Hình 2C) cho kết quả phân tách trên bản mỏng với số vệt sắc ký (4 vệt, mỗi vệt tương ứng với một hoạt chất) thấp hơn số vệt sắc ký khi phân tách từ mẫu dịch chiết lá chanh không qua cô quay chân không (Hình $2 \mathrm{~K}$ ) (9 vệt sắc ký). Đồng thời, kết quả Hình 2 cũng cho thấy duy nhất chỉ có thể phát hiện được citral (một loại hoạt chất sinh học có tác dụng diệt khuẩn) khi thực hiện TLC với mẫu dịch chiết không cô quay chân không.

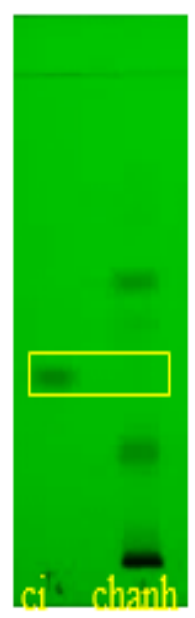

(C)

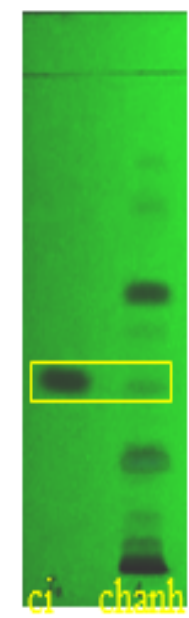

(K)
Hình 2. Sắc ký đồ của dịch chiết từ lá chanh trải qua cô quay chân không $(\mathrm{C})$ và không cô quay chân không $(\mathrm{K})$ khi khai triển trong $\mathrm{TE}$ và quan sát bằng $\mathrm{UV}(\lambda=254 \mathrm{~nm})$.

\subsubsection{Kết quả phân tách hoạt chất từ chiết xuất cây dược liệu theo loại dung môi khai triển sắc $\mathrm{ký}$}

Sử dụng dung môi khai triển sắc ký là bước quan trọng quyết định khả năng phân tách trên bản mỏng những hoạt chất trong thành phần chiết xuất của dược liệu. Trong nghiên cứu này, chiết xuất từ cao thô lá chanh và lá sim cho kêt quả phân tách tốt hơn khi khai triển trong dung môi TE so với khi sử dụng dung môi CEF. Số lượng các vệt sắc ký trong mẫu cao thô lá chanh và lá sim đều cho kết quả cao hơn khi khai triển bằng dung môi TE (9 và 10 vệt) so với dung môi CEF (5 và 7 vệt) (Hình 3.I và 3.II). Trái lại, sắc ký đồ của cao thô lá trà xanh khi khai triển trong CEF cho kết quả phân tách tốt hơn so với khai triển trong TE. Số lượng các vệt sắc ký trong trong mẫu cao thô lá trà xanh có thể phát hiện được khi khai triển trong các hệ dung môi CEF và $\mathrm{TE}$ lần lượt là 11 và 4 (Hình 3.III). Khả năng phân tách của các hệ dung môi tùy thuộc vào tính phân cực của các chất, hợp chất có trong dịch chiết. Nghiên cứu của Eloff \& ctv. (2011) cho thấy hệ dung môi CEF thích hợp nhất khi phân tách các chất hợp chất có tính phân cực trung bình. Trong khi Wagner \& Bladt (1996) khẳng định hệ dung môi TE thích hợp dùng trong phân tích và so sánh tất cả các tinh dầu thiết yếu quan trọng (trong đó có citral). Như vậy, dựa vào kêt quả trên, TE sẽ được chọn làm hệ dung môi khai triển khi thực hiện sắc ký đối với mẫu cao thô lá chanh và sim; trong khi CEF sẽ được chọn làm hệ dung môi khai triển khi thực hiện sắc ký đối với mẫu cao thô lá trà xanh trong các thử nghiệm tiếp theo.

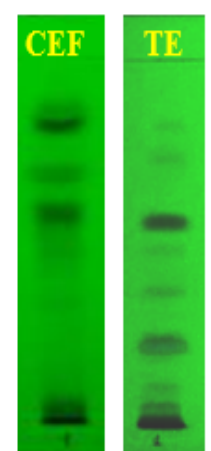

(I)

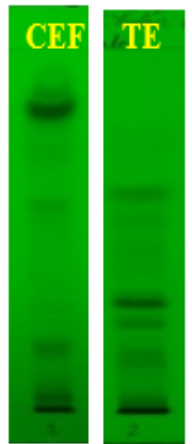

(II)

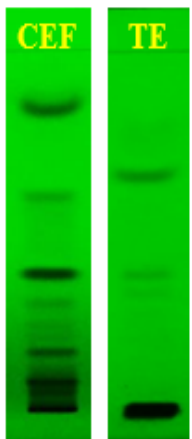

(III)
Hình 3. Kết quả phân tách thành phần hoạt chất từ cao thô của lá chanh (I), lá sim (II) và lá trà xanh (III) quan sát với UV ( $\lambda=254 \mathrm{~nm})$. 


\subsection{Xác định sự hiện diện hoạt chất chính có tác dụng dược lý từ thành phần chiết xuất của mỗi loại cây dược liệu}

Kết quả nghiên cứu (Hình 4 và 5) cho thấy khả năng phát hiện sự hiện diện của citral, catechine hydrate và rhodomyrtone trong chiết xuất của các loại dược liệu dùng trong nghiên cứu bằng kỹ thuật TLC. Kết quả này cũng cho thấy khả năng phát hiện citral, rhodomyrtone và catechin hydrate tương đương nhau khi quan sát bằng UV $(\lambda=254 \mathrm{~nm})$ cũng như bằng mắt thường với thuốc thử vanillin. Sự hiện diện của các hoạt chất có hoạt tính dược học (citral, catechine hydrate và rhodomyrtone) cũng được khẳng định qua hệ số di chuyển trên bản mỏng (Rf) khi so sánh với chất chuẩn của 3 hoạt chất này (Bảng 3 ).

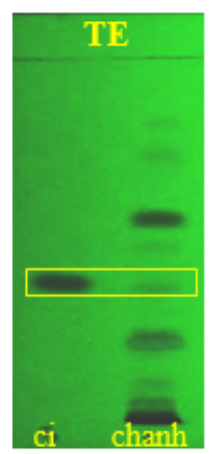

(I)

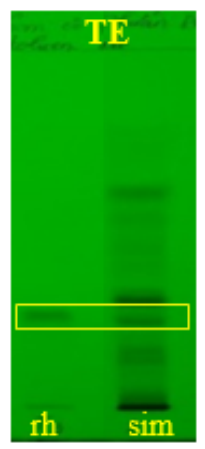

(II)

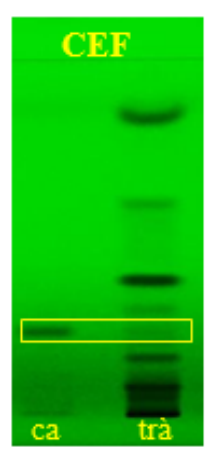

(III)
Hình 4. Kết quả phân tách thành phần hoạt chất từ cao thô của lá chanh (I), lá sim (II) và lá trà xanh (III) quan sát với UV $(\lambda=254 \mathrm{~nm})$.

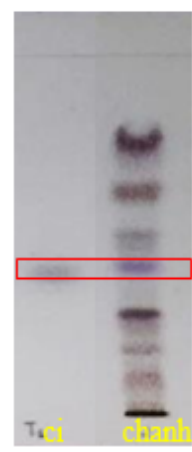

(I)

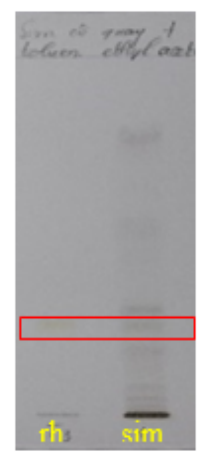

(II)

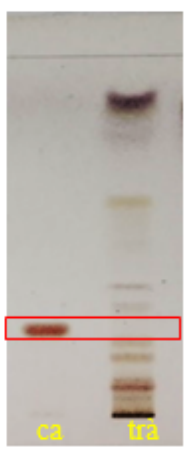

(III)
Hình 5. Sắc ký đồ của cao thô chiết bằng acetone từ lá chanh (I), lá sim (II) và lá trà xanh (III) quan sát sau khi phun thuốc thử.

Kết quả của nghiên cứu này cho thấy khả
Bảng 3. Giá trị Rf của các hoạt chất chính có hoạt lực dược học trong thành phần chiết xuất từ 3 loại cây dược liệu

\begin{tabular}{lcc}
\hline Tên hoạt chất & Dung môi khai triển & Rf \\
\hline Catechin hydrate & CEF & 0,23 \\
Citral & TE & 0,38 \\
Rhodomyrtone & TE & 0,43 \\
\hline
\end{tabular}

năng ứng dụng phương pháp TLC trong phát hiện những hoạt chất có giá trị trong dược học. Các loại catechine trong trà xanh có khả năng kháng lại đối với cả vi khuẩn Gram dương và vi khuẩn Gram âm. Đặc biệt, epigallo-catechin gallate (EGCG) được chứng minh có khả năng ức chế sự phát triển của vi khuẩn nhiễm trùng đường miệng trên chó và ngăn cản sự hình thành màng sinh học (biofilm) của Streptococcus mutan (Lanlan \& ctv., 2016). Ngoài ra, các dẫn xuất khác nhau của catechine đã được chứng minh có tác dụng làm giảm số lượng bào tử sinh ra từ vi khuẩn kị khí như Clostridium botulinum và Clostridium butyricum (Yukiko \& ctv., 2005). Nhiều nghiên cứu đã báo cáo về khả năng kháng khuẩn đặc hiệu của rhodomyrtone trong dịch chiết lá sim đối với các vi khuẩn Gram dương và quan trọng hơn là hoạt chất này có tác dụng trên cả các vi khuẩn đã đề kháng với nhiều loại kháng sinh. Rhodomyrtone sử dụng thực nghiệm trong nhiều nghiên cứu khác nhau cho thấy có tác dụng giảm sự xâm lấn và bám dính của vi khuẩn trong mô dưới da của bầu vú bò, điều này giúp điều trị bệnh viêm vú trên bò sữa ở thể lâm sàng và cận lâm sàng (Surasak \& ctv., 2012; Sukanlaya \& ctv., 2013; Mordmuang \& ctv., 2015). Chính vì vậy, hoạt chất này được đánh giá như là một loại thuốc kháng sinh mới có nguồn gốc từ tự nhiên (Surasak \& ctv., 2009). Ngoài ra, citral cũng được chứng minh có khả năng ức chế sự phát triển đối với cả vi khuẩn Gram dương, Gram âm và nấm (Grace, 1989).

Giới hạn phát hiện (LOD) của citral, rhdomyrtone và catechin hydrate trong phương pháp được xác định ở các mức $195 \mathrm{ng} /$ vệt, $321,5 \mathrm{ng} /$ vệt và 625 ng/vệt (Hình 6). Nghiên cứu của Dinesh \& ctv. (2015) cho kết quả LOD của catechin là 13,37 ng/vệt khi sử dụng phương pháp HPTLC (Highperformance thin-layer chromatography) trong phân tích thành phần của trà xanh. Bước đầu cho thấy với phương pháp TLC, hàm lượng của hoạt chất trong chiết xuất cần ở mức cao hơn để có thể xác định sự hiện diện của hoạt chất trong thành phần cây dược liệu. 


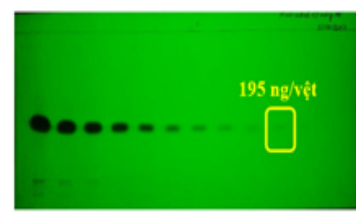

(I)

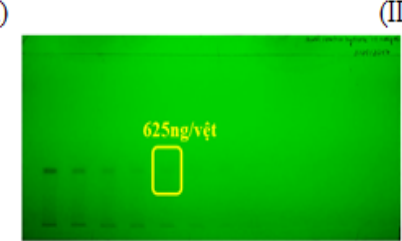

(III)

Hình 6. Sắc ký đồ của cao thô chiết bằng acetone từ lá chanh (I), lá sim (II) và lá trà xanh (III) quan sát sau khi phun thuốc thử.

\section{Kết Luận và Đề Nghị}

Trong phạm vi nghiên cứu này thuật TLC cho thấy khả năng phân tách tốt thành phần hoạt chất có trong chiết xuất từ cây dược liệu và cho phép xác định hoạt chất có hoạt tính dược lực trong thành phần dịch chiết dựa vào chất chuẩn và chỉ số Rf. Những nghiên cứu tiếp theo cần chuẩn hoá thêm một số thông số về dung môi chiết xuất và khai triển phù hợp cho mỗi loại cây dược liệu để có thể sử dụng phương pháp TLC trong phân tích thành phần nhiều loại cây nguyên liệu có giá trị dược học tại Việt Nam.

\section{Lời Cảm Ơn}

Nhóm nghiên cứu chân thành cảm ơn quỹ nghiên cứu Khoa học và công nghệ, Trường Đại học Nông Lâm, TP.HCM; Khoa Chăn nuôi - Thú y; Bộ môn Khoa học Sinh học Thú y đã tài trợ và tạo điều kiện để nhóm thực hiện nghiên cứu này. Đồng thời, nhóm nghiên cứu xin gửi lời cám ơn sâu sắc đến các bạn Lâm Ánh Tuyết, Nguyễn Thị Họa Mi và Nguyễn Thị Ngân Giang đã tích cực hỗ trợ cho nghiên cứu này.

\section{Tài Liệu Tham Khảo (References)}

Asadhawut, H. (2010). Chemical Constituents from Rhodomyrtus tomentosa (Aiton) Hassk and antibacterial activity (Unpublished doctoral dissertation). Prince of Songkla University, Hat Yai, Thailand.

Ashray, G. (2012). Extraction, purification, identification and estimation of catechins from Camellia sinensis (Unpublished bachelor's thesis). Institute of Himalayan Bioresource Technology (IHBT), Palampur, India.
Auemphon, M., Shiv, S., Usa, C., \& Voravuthikunchai, S. P. (2015). Effects of Rhodomyrtus tomentosa leaf extract on staphylococcal adhesion and invasion in bovine udder epidermal tissue model. Nutrients $7(10)$, 8503-8517.

Chao, S., Kaikuo, S., Xiaorong, Z., Yi, S., Yue, S., Yifei, C., Zhenyu, J., Huihui, S., Zheng, S., \& Xiaodong, X. (2016). Antimicrobial activity and possible mechanism of action of citral against Cronobacter sakazakii. PloS One 11(7), e0159006.

Charles, L., \& Kayanja, I. B. F. (2012). Vitro antimicrobial activity of crude extracts of Erythrina abyssinica and Capsicum annum in poultry diseases control in the South Western Agro-Ecological zone of Uganda. In Perez-Marin, C. C. (Ed.). A Bird's-Eye View of Veterinary Medicine (ed., 597-614). London, United Kingdom: InTech.

Dinesh, K., Ashu, G., \& Upendra, S. (2015). Determination of theanine and catechin in Camellia sinensis (Kangra tea) leaves by HPTLC and NMR techniques. Food Analytical Methods 9(6), 1666-1674.

Do, L. T. (2004). Medicinal plants and herbs in Vietnam. Ha Noi, Vietnam: Medical Publishing House.

Eloff, J. N. (1998). Which extractant should be used for the screening and isolation of antimicrobial components from plants? Journal of Ethnopharmacology $60(1), 1-8$.

Eloff, J. N., Ntloedibe, D. T., \& van Brummelen, R. (2011). A simplified but effective method for the quality control of medicinal plants by planar chromatography. African Journal of Traditional, Complementary and Alternative Medicines 8(S), 1-12.

Grace, O. O. (1989). Evaluation of the antimicrobial activity of citral. Letters in Applied Microbiology 9(3), 105-108.

Hiranrat, A. (2010). Chemical constituent from Rhodomyrtus tomentosa (Aiton) Hassk. and antibacterial activity (Doctoral Thesis). Prince of Songkla University, Hat Yai, Thailand.

Lanlan, B., Shiaki, T., Tasuke, A., Hiroshi, Y., Kumiko, I., Hiroyuki, M., \& Emiko, I. (2016). Antimicrobial activity of tea catechin against canine oral bacteria and the functional mechanisms. The Journal of Veterinary Medical Science 78(9), 1439-1445.

Maria, C. A. L., André, P. B. B., Janiere, P. S., Felipe, Q. S. G., \& Edeltrudes, O. L. (2014). Evaluation of antifungal activity and mechanism of action of citral against Candida albicans. Evidence-Based Complementary and Alternative Medicine 2014, 1-9.

Matthew, J. C., Aishwarya, I., Baxter, B., \& Ian, E. C. (2017). Developing new antimicrobial therapies: are synergistic combinations of plant extracts/compounds with conventional antibiotics the solution?. Pharmacognosy Reviews 11(22), 57-72.

Mordmuang, A., Shankar, S., Chethanond, U., \& Voravuthikunchai, S. P. (2015). Effects of Rhodomyrtus tomentosa leaf extract on staphylococcal adhesion and 
invasion in bovine udder epidermal tissue model. $\mathrm{Nu}$ trients 7(10), 8503-8517.

Sibanda, T., \& Okoh, A. I. (2007). The challenges of overcoming antibiotic resistance: Plant extracts as potential sources of antimicrobial and resistance modifying agents. African Journal of Biotechnology 6(25), 28862896.

Sukanlaya, L., Peter, W. T., \& Voravuthikunchai S. P. (2013). Antibacterial mechanisms of rhodomyrtone against important hospital-acquired antibioticresistant pathogenic bacteria. Journal of Medical Microbiology 62(Pt 1), 78-85.

Surasak, L., Erik, N. T., Thijs, R. H. M. K., Sjouke, P., Hiranrat, A., Mahabusarakam, W., Voravuthikunchai, S. P., Jan, M. V. D., \& Kayser, O. (2009). Rhodomyrtone: a new candidate as natural antibacterial drug from Rhodomyrtus tomentosa. Phytomedicine 16(6-7), 645-651.

Surasak, L., Oliver, K., \& Voravuthikunchai, S. P. (2012). Antibacterial activity of Rhodomyrtus tomentosa (Aiton) Hassk. leaf extract against clinical isolates of Streptococcus pyogenes. Evidence-Based Complementary and Alternative Medicine 2012, 1-6.
VPC (Vietnam Pharmacopoeia Center). (2009). Vietnamese pharmacopoeia IV. Ha Noi, Vietnam: Ministry of Health.

Wagner, H., \& Bladt, S. (1996). Plant drug analysis; A thin layer chromatography atlas ( $2^{\text {nd }}$ ed.). Berlin, Germany: Springer.

Wanda, C. R. (2014). The antimicrobial possibilities of green tea. Frontiers in Microbiology 5, 434.

Yukiko, H. K., Akiko, Y., Miho, S., Tsutomu, O., Yuji, M., Minoru, H., Kazuo, K., \& Yoshiko, S. K. (2005). Antibacterial action on pathogenic bacterial spore by green tea catechins. Journal of the Science of Food and Agriculture 85(14), 2354-2361. 